\title{
Congenital cerebral malaria: a masquerader in a neonate
}

\author{
Ezinne I. Nwaneli ${ }^{1,2^{*}} \mathbb{0}$, Chisom A. Nri-ezedi ${ }^{1,2}$, Kenneth N. Okeke ${ }^{1,2}$, Emeka S. Edokwe $^{1,2}$, Sylvia T. Echendu ${ }^{3}$ and \\ Kenechukwu K. Iloh ${ }^{4}$
}

\begin{abstract}
Background: Congenital malaria, which is caused by vertical transmission of malaria parasites, is a potentially fatal condition. Despite Africa's high malaria burden, congenital malaria is not routinely screened for, and thus may go undiagnosed. Malaria, if not treated promptly, can quickly progress to severe forms and result in death. Severe congenital malaria is believed to be uncommon in neonates due to maternal antibodies, fetal haemoglobin, and the placenta's sieving effect. The majority of reported cases were classified as having severe anaemia. Following a thorough review of the literature, only one case of congenital cerebral malaria (CCM) has been reported, and it was misdiagnosed.

Case presentation: A 5-day-old Nigerian neonate born to an apparently healthy mother initially displayed characteristics consistent with neonatal sepsis and severe neonatal hyperbilirubinaemia. He quickly developed characteristics consistent with meningitis. Surprisingly, the peripheral blood film revealed evidence of malaria parasites, which was immediately confirmed by Giemsa-stained thick and thin blood film microscopy for malaria. The patient was diagnosed with congenital cerebral malaria. The medication was modified to parenteral artesunate followed by oral artemisinin combination therapy. The neonate recovered fully and had no neurological deficits on follow up.
\end{abstract}

Conclusion: Because CCM and infant meningitis have similar clinical presentations, CCM could be misdiagnosed and lead to death if there isn't a high index of suspicion.

Keywords: Complicated malaria, Newborn, Seizures, Early onset neonatal sepsis, Neonatal meningitis

\section{Background}

Malaria is primarily transmitted to humans through the bites of infected female Anopheles mosquitoes, but it can also be transmitted via blood transfusion, organ donation or from a pregnant woman to her fetus [1-3]. Malaria is acquired through mosquito bites following delivery [4]. Africa continues to have the world's highest malaria burden and malaria is a significant public health problem in Nigeria, where it causes more cases and deaths than any other disease [5]. Available hospital review shows that

\footnotetext{
*Correspondence: einwaneli@unizik.edu.ng

${ }^{1}$ Department of Paediatrics, Faculty of Medicine, Nnamdi Azikiwe University, Awka, Anambra State, Nigeria

Full list of author information is available at the end of the article
}

malaria accounted for $60 \%$ of outpatient visits to health facilities, $30 \%$ of child mortality, $25 \%$ of infant mortality, and $11 \%$ of maternal mortality [6]. Repeated malaria infection results in the acquisition of agglutinating antibodies directed against the parasite-encoded variant surface antigen (VSA) expressed on parasitized red blood cells [7]. Repeated infection occurs in stable transmission areas, and thus residence in such areas provides some protection to the population.

In endemic areas such as Nigeria, where mothers have developed significant immunity to malaria, Plasmodium falciparum infection during pregnancy does not always result in symptomatic illness [8]. As a result, congenital malaria in an ill neonate may go unnoticed if the mother appears to be otherwise healthy. It is widely believed that 
the placenta serves as an effective barrier against malaria parasite transmission $[9,10]$. Additionally, the newborn receives some immunoglobin $\mathrm{G}$ (IgG) antibodies against VSA from the mother, which provides some protection [7]. Furthermore, it has been demonstrated that fetal haemoglobin $(\mathrm{HbF})$ protects against high parasitaemia, thereby preventing severe disease [11]. These features may contribute to physicians' misdiagnosis of congenital and neonatal malaria, even in severe forms. It is worth noting, however, that estimated prevalence of congenital malaria was reported as 40.4/1000 in sub-Saharan Africa, based on a comprehensive review and meta-analysis of 22 observational studies by Dawang et al. [12]. This study complements a recent meta-analysis that examined 8148 newborns and estimated a global prevalence of $6.9 \%$ with considerable inter-country variability (with estimates as high as $46.7 \%$ in Nigeria) [13]. Furthermore, even in the absence of congenital malaria, placental malaria increases the risk of perinatal morbidity and mortality, including low birth weight, intrauterine growth restriction, premature labour, and intrauterine fetal death [14].

Congenital malaria is diagnosed by the detection of asexual malaria parasites on a blood smear of the newborn's peripheral blood within the first 7 days of life $[1$, 15]. Passive immunity transmitted to the newborn may delay or alter the severity of symptoms for up to 6 weeks following delivery, making it difficult to differentiate between congenital and neonatal malaria [16]. Regardless of the clinical picture, neonates born to women who had malaria within the 7 days preceding birth should have a blood film checked for malaria parasites and be monitored weekly for the 1st month to increase the likelihood of early detection of congenital malaria [4].

Cerebral malaria is defined by the World Health Organization (WHO) as a clinical state characterized by a coma lasting at least $1 \mathrm{~h}$ after the end of a seizure or correction of hypoglycaemia, asexual $P$. falciparum parasites on peripheral blood smears, and no other explanation for the coma [17]. Physical signs of seizure activity in neonates are frequently imperceptible and subtle [18]. Subtle seizures account for half of neonatal seizures and are often difficult to distinguish from normal interictal behaviors or physiological phenomena [19]. These include tonic, horizontal deviation of the eyes with or without jerking, blinking or fluttering of the eyelids, sucking, smacking, or other oral-buccal-lingual movements, swimming or pedaling movements, and, on rare occasions, apnoeic spells [20]. Failure to recognize the condition can be fatal, as these patients are hypoxic and hypercarbic due to hypoventilation and are at risk of aspiration [18]. If left untreated, cerebral malaria is always fatal [18]. Malaria during pregnancy is thought to be responsible for 100,000 neonatal deaths each year
[8]. It is preventable during pregnancy with intermittent preventive treatment of malaria in pregnancy (IPTp) with sulfadoxine-pyrimethamine (SP), which has been shown to reduce neonatal mortality by up to $61 \%$ [21]. IPTp recommends a minimum of three SP doses, 1 month apart, starting after quickening (approximately 18 weeks gestation), and routinely delivered at antenatal clinics [22]. Nigeria adopted the IPTp strategy in 2005, with varying levels of implementation across the country's states [23]. According to the 2018 Nigeria Demographic and Health Survey, $63 \%$ of women received at least one dose of SP, but $16.6 \%$ received at least three doses [24].

In endemic locales, the reported incidence of congenital malaria ranged from 0 to $37 \%$ [25-27], and majority of these cases were not serious and were discovered during routine neonatal screening. Severe anaemia is the most usually reported complication of malaria [25, 26, 28], Following a thorough examination of the literature, the investigators discovered only one incidence of congenital cerebral malaria, which occurred in India [29].

\section{Case report}

A 5-day-old male neonate presented with 3 days history of yellowness of the body and 2 days history of poor suckling and excessive sleep. The yellowness of the body began on the face on the 2nd day of life and spread to other parts of the body. He sucked for less than 2 min on the mother's breast on the 3rd day of life, compared to approximately $20 \mathrm{~min}$ prior to the illness. He was constantly asleep, and even when a perceived painful stimulus was applied, he cried poorly and low pitched. No fever or obvious convulsions were observed by the parents. Since birth, his mother had been administering $2.5 \mathrm{mls}$ of oral paracetamol three times daily on the advice of a nurse. While pregnant, the mother received two doses of tetanus toxoid, but did not receive intermittent preventive treatment for malaria. She had no febrile illness throughout the pregnancy, but experienced foul-smelling creamy and itchy vaginal discharge in the final trimester, which was resolved with self-prescribed nystatin pessary. There was no prior history of premature membrane rupture. The pregnancy was carried to term, and the birth occurred vaginally. He was born crying and weighing $3.2 \mathrm{~kg}$. The mother had no history of postpartum fever, and her lochia was not offensive. Due to a delay in lactation, the baby was given pre-lacteal feeds (infant formula) only on the 1st day of life, but by the second day, the baby was exclusively on breast milk and sucking effectively. On his 2nd day of life, he received BCG, oral polio 1, and hepatitis $B$ virus vaccinations. He is the second child of civil servant parents, and his female elder sibling had no history of neonatal jaundice. The parents had O Rhesus positive blood groups, and there was no family history 
of glucose-6-phosphate dehydrogenase deficiency or the use of naphthalene balls on the baby's clothing.

$\mathrm{He}$ was extremely irritable, in respiratory distress, febrile with an axillary temperature of $38^{\circ} \mathrm{C}$, moderately pale, icteric to the palms and soles, and acyanosed upon presentation. The respiratory rate (RR) was 68 breaths per minute, the heart rate (HR) was 162 beats per minute, the blood pressure (BP) was $102 / 51 \mathrm{mmHg}$, the oxygen saturation $\left(\mathrm{SPO}_{2}\right)$ was 92 percent, and he weighed $2.98 \mathrm{~kg}$. He had a Blantyre coma score (BCS) of $4 / 5$ and a flat and soft anterior fontanelle (2.5 $\mathrm{cm}$ in diameter). He had normotonia but suboptimal primitive reflexes (Moro and palmar grasp). He also had hepatosplenomegaly and a wet but clean umbilical stump. The examination of the respiratory and cardiovascular systems revealed no abnormalities. A presumptive diagnosis of early onset neonatal sepsis and severe neonatal hyperbilirubinaemia was made. The laboratory result that was immediately available (random blood glucose) was $70 \mathrm{mg} / \mathrm{dl}$. Serum bilirubin, urinalysis, urine microscopy, culture and sensitivity $(\mathrm{m} / \mathrm{c} / \mathrm{s})$, umbilical swab $\mathrm{m} / \mathrm{c} / \mathrm{s}$, complete blood count, peripheral blood film, direct and indirect Coombs tests, glucose-6-phosphate dehydrogenase, cerebrospinal fluid $\mathrm{m} / \mathrm{c} / \mathrm{s}$, protein and glucose, serum electrolytes, urea and creatinine were also requested. He was started on intravenous ceftazidime $(100 \mathrm{mg} / \mathrm{kg})$ and geniticin $(5 \mathrm{mg} / \mathrm{kg}$ ), both in two divided doses $12 \mathrm{~h}$ apart, and a maintenance dose of $10 \%$ dextrose water. The patient received a double exchange blood transfusion (EBT) that was well tolerated. Following that, intensive phototherapy was continued. Breastmilk was fed $4 \mathrm{~h}$ after EBT via a nasogastric tube and was tolerated.

Thirteen hours into the admission, while still being monitored continuously for vital signs, his $\mathrm{SPO}_{2}$ was observed to decrease intermittently to approximately $30 \%$ to $40 \%$, before increasing to approximately 80 to $90 \%$ after approximately 30 to $60 \mathrm{~s}$. In $1 \mathrm{~h}$, eight episodes were recorded. Further examination revealed that he was experiencing subtle seizures (apneic attacks) during periods when his $\mathrm{SPO}_{2}$ decreased. His RR was 64 to 70 breaths per minute (in between apneic attacks) and his HR was 120 beats per minute during the attack and increasing to 182 beats per minute afterwards. There was also an increase in his temperature $\left(38.2^{\circ} \mathrm{C}\right)$ and blood pressure $(115 / 75 \mathrm{mmHg})$. His BCS was $2 / 5$, his anterior fontanelle was tense, and he was hypertonic with an opthostonic posture. RBG was $118 \mathrm{mg} /$ $\mathrm{dl}$ on repeat. The baby was placed on intranasal oxygen, and his drug prescription was modified to include three doses of intravenous (IV) mannitol $(1 \mathrm{~g} / \mathrm{kg} / \mathrm{dose}$ over $30 \mathrm{~min}) 8 \mathrm{~h}$ apart, frusemide $(2 \mathrm{mg} / \mathrm{kg} /$ dose to follow each dose of mannitol), diazepam $(0.2 \mathrm{mg} / \mathrm{kg} /$ dose over $10 \mathrm{~min}$ ), phenobarbitone (loading dose of
$20 \mathrm{mg} / \mathrm{kg}$, maintenance dose of $5 \mathrm{mg} / \mathrm{kg}$ in two divided doses $12 \mathrm{~h}$ apart), and dexamethasone $0.2 \mathrm{mg} / \mathrm{kg} / \mathrm{dose}$ every $12 \mathrm{~h}$. Even though apneic attacks did not recur following anticonvulsants, the patient maintained an opithostonic posture.

The peripheral blood film result (requested prior to the EBT) revealed normocytic, normochromic red blood cells, but also significant malaria parasites. A Giemsa-stained thick and thin blood film was immediately requested for malaria microscopy and revealed trophozoites of $P$. falciparum with a parasite density of 8341 parasites $/ \mu \mathrm{l}$. Other investigations conducted prior to the EBT revealed a total serum bilirubin of $30 \mathrm{mg} /$ $\mathrm{dl}$ and conjugated bilirubin of $1.9 \mathrm{mg} / \mathrm{dl}$. Complete blood count showed leucopenia of $2.0 \times 10^{9} / 1$, with differential neutrophils, lymphocytes and monocytes percentage of $30 \%, 69 \%$ and $1 \%$ respectively. Haematocrit level was $35.1 \%$ and he had thrombocytopenia $(90,000 /$ $\mathrm{mm}^{3}$ ). Urinalysis result revealed a deep amber and clear urine with presence of protein, urobilinogen and bilirubin. CSF analysis, urine $\mathrm{m} / \mathrm{c} / \mathrm{s}$, umbilical swab $\mathrm{m} / \mathrm{c} / \mathrm{s}$, serum electrolytes, urea and creatinine, both direct and indirect Coombs test returned no significant abnormality. Total serum bilirubin was $8.5 \mathrm{mg} / \mathrm{dl}$ following EBT, while conjugated bilirubin was $1.5 \mathrm{mg} / \mathrm{dl}$. The patient was diagnosed with severe congenital malaria (cerebral malaria). Intravenous dexamethasone and antibiotics were stopped. Intravenous artesunate was prescribed at a dose of $3 \mathrm{mg} / \mathrm{kg}$ to be given at $0 \mathrm{~h}, 12 \mathrm{~h}$ and subsequently 24 hourly till the patient regains consciousness.

Following commencement of intravenous artesunate $\left(\right.$ Rekmal $\left.^{\circledR}\right)$, the patient's consciousness gradually improved; by the second dose, he was no longer in an opisthotonic state, and by the fourth dose, he had regained complete consciousness and was able to suckle on his mother's breast. After the fifth IV dose of artesunate, a 3-day course of oral artesunate-amodiaquine was initiated (artesunate, Artesunat ${ }^{\circledR} 4 \mathrm{mg} / \mathrm{kg}$ / day and amodiaquine, Camoquin ${ }^{\circledR} 10 \mathrm{mg}$ base $/ \mathrm{kg} /$ day). Intravenous phenobarbitone was gradually tapered off. The mother complained of a headache, fever, and chills on the 3rd day following presentation. A rapid diagnostic test for malaria histidine-rich protein 2 (HRP2) was positive, and she received a full course of ACT with clinical recovery. On the 5th day, the patient was discharged, and a repeat malaria microscopy performed that day was negative. The mother was counseled on the importance of intermittent preventive treatment during pregnancy, in addition to other malaria prevention measures. The patient was followed up for 1 year and no neurologic deficit was discovered during followup examinations of the central nervous system. 


\section{Discussion}

Congenital malaria is defined as the presence of malarial parasites in a baby's cord blood or peripheral smear within 7 days of birth $[4,29]$. This occurs as a result of vertical malaria parasite transmission prior to delivery. This case describes congenital malaria with symptoms beginning on the 3rd day of life and demonstrable hyperparasitaemia on the 5th day of life. Congenital malaria is reported to be uncommon, with the majority of cases occurring without symptoms [15, 26, 30] and approximately $7 \%$ to $10 \%$ of cases symptomatic [10, 31]. Congenital malaria has been documented to present with anaemia, fever, hepatosplenomegaly, poor feeding, lethargy, irritability, and jauncice $[4,16,32,33]$. All the aforementioned symptoms were observed in the neonate who was also experiencing subtle seizures (apneic attacks), an unarousable coma, and opithostonic posturing. Following careful literature search, only a case of congenital cerebral malaria has been reported, and this was reported in Mumbai, India [29]. The Indian neonate presented on the 4th day of life with a history of fever and reduced feeding. Additionally, he was found to be irritable, febrile, icteric, exhibiting opisthotonic posture, tonic movements, hypertonic, and possessing a risus sardonicus-like facies [29]. The index neonate, like the Indian neonate, had hypertonia, and opithostonic posturing; however, the subtle pattern of their seizures was different. The neonate also had an unarousable coma which lasted more than $1 \mathrm{~h}$.

Seizures and unarousable coma are known features of severe $P$. falciparum malaria referred to as cerebral malaria [18]. For cerebral malaria to be entertained in children, prolonged unconsciousness lasting more than an hour is required [18]. Due to the overlap of cerebral malaria and meningitis symptoms, a low index of suspicion, and a lack of screening, congenital malaria may be misdiagnosed as neonatal sepsis or neonatal meningitis, as was the case in the Nigerian and Indian neonates. In both cases, it was an unintentional examination of the peripheral blood smear to determine the red cell morphology of the icteric neonates that revealed haemoparasites within the red blood cells. Punta et al. reported a similar pattern of accidental discovery of malaria parasites in the blood of a neonate who was initially diagnosed with neonatal sepsis [34]. As required, the index patient was also examined for additional causes of altered consciousness, including hypoglycemia, meningitis, electrolyte imbalance, and uraemia [18], but none were found.

Malaria was confirmed using the gold standard of Giemsa-stained thick and thin blood film microscopy [35]. Although parasitaemia in newborns is typically low $[15,36,37]$, this was not the case in the neonate who had high parasitaemia of 8341 parasites/ $\mu$ l $[38,39]$. Vedang et al. also reported high parasitaemia with a parasite index of $5 \%$ in the Indian neonate [20]. The presentation of clinical disease in this Nigerian neonate by the 3rd day suggests that the transmission to the fetus may have occurred in utero even when the mother was asymptomatic. Relatively high in utero parasitaemia developed despite presumed maternal immunity and the reduced parasite growth rates associated with fetal haemoglobin [11]. The patient had full clinical and parasitological recovery following treatment with intravenous artesunate according to the WHO treatment guideline for complicated malaria [40]. The presence of maternal HRP2 antigenaemia confirmed maternal malaria infection. This confirms a previous finding that despite being asymptomatic, a mother living in a malaria-endemic area can transmit the parasite to her fetus. Given the speed with which malaria rapid antigen test results are available and the lack of specialized skill required for its performance when compared to malaria microscopy, it could also be used to screen sick neonates for malaria in the interim, while waiting for malaria microscopy, which requires expertise but is the gold standard for diagnosis. This will help in the early detection and treatment of congenital malaria. Although no guidelines exist to assess impairments or guide rehabilitation following cerebral malaria [41], a follow-up evaluation of the central nervous system of the patient was unremarkable.

\section{Conclusions}

Cerebral malaria can present as a manifestation of congenital malaria and should be considered in patients who present with seizures and an unarousable coma. Sick neonates born to asymptomatic mothers in malaria-endemic areas should also be promptly investigated for malaria. Although additional data are needed in neonates, intravenous artesunate followed by oral artesunate-amodiaquine treatment appeared to be safe and effective.

\section{Abbreviations \\ CCM: Congenital cerebral malaria; VSA: Variant surface antigen; IgG: Immuno- globin G; HbF: Fetal haemoglobin; IPTp: Intermittent presumptive treat- ment of malaria in pregnancy; $\mathrm{BP}$ : Blood pressure; $\mathrm{SPO}_{2}$ : Oxygen saturation; BCS: Blantyre coma score; M/C/S: Microscopy, culture and sensitivity; HRP2: Histidine-rich protein 2.}

\section{Acknowledgements}

The authors acknowledge Eldorado Multispecialist Hospital and all staff at the Eldorado Multispecialist Neonatal intensive care unit for their various contributions to this work.

\section{Authors' contributions}

EIN: conceived the idea and wrote the manuscript. NAC, ONK, EE, EAS, IK: participated in writing the manuscript. All authors read and approved the final manuscript. 


\section{Funding}

The case report was not funded.

\section{Availability of data or materials}

The clinical data of the patient is available upon request.

\section{Declarations}

\section{Ethics approval}

Not applicable.

\section{Consent for publication}

Written informed consent for publication of their clinical details was obtained from the parent of the patient. A copy of the consent form is available for review by the Editor of this journal.

\section{Competing interests}

The authors declare that they have no completing interests.

\section{Author details}

${ }^{1}$ Department of Paediatrics, Faculty of Medicine, Nnamdi Azikiwe University, Awka, Anambra State, Nigeria. ${ }^{2}$ Department of Paediatrics, Nnamdi Azikiwe University Teaching Hospital, Nnewi, Anambra State, Nigeria. ${ }^{3}$ Life International Hospital, Awka, Anambra State, Nigeria. ${ }^{4}$ Department of Paediatrics, University of Nigeria Teaching Hospital, Ituku-Ozalla, Enugu State, Nigeria.

Received: 15 November 2021 Accepted: 19 January 2022 Published online: 05 February 2022

\section{References}

1. White NJ, Breman JG. Malaria and babesiosis caused by red blood cell parasites. In: Braunwald E, Fauci AS, Kasper DL, Hauser SL, Longo DL, Jameson JL, editors. Harrison's principles of internal medicine. 15th ed. New York: Mc-Graw-Hill; 2001. p. 1203-13.

2. WHO. Malaria fact sheet. Geneva: World Health Organization. www. who.int.mediacentre/factsheets/fs094/en/. Accessed 10 Sept 2021.

3. Kitchen AD, Chiodini PL. Malaria and blood transfusion. Vox Sang. 2006;90:77-84

4. Olupot-Olupot P, Eregu El, Naizuli K, Ikiror J, Akom L, Burgoine K. Neonatal and congenital malaria: a case series in malaria endemic eastern Uganda. Malar J. 2018;17:171.

5. WHO. World malaria report 2020. Geneva: World Health Organization; 2020. https://www.who.int/docs/default-source/malaria/world-malar ia-report/978924001591-double-page-view.pdf?sfvrsn=2c24349d_5.

6. Nigeria Malaria Fact Sheet_US Department of State. 2011. http://niger ia.usembassy.gov. Accessed 31 Aug 2021

7. Ofori MF, Dodoo D, Staalse T, Kurtzhals JA, Koram K, Theander TG, et al. Malaria- induced acquisition of antibodies to Plasmodium falciparum variant surface antigens. Infect Immun. 2002;70:2982-8.

8. Eisele TP, Larsen DA, Walker N, Cibulskis RE, Yukich JO, Zikusooka CM, et al. Estimates of child deaths prevented from malaria prevention scale-up in Africa 2001-2010. Malar J. 2012;11:93.

9. Snow RW, Nahlen B, Palmer A, Donnelly CA, Gupta S, Marsh K. Risk of severe malaria among African infants; direct evidence of clinical protection during early infancy. J Infect Dis. 1998:3:819-22.

10. McGregor IA, Wilson ME, Billewicz WZ. Malaria infection of the placenta in The Gambia, West Africa; its incidence and relationship to still birth, birth weight, and placenta weight. Trans R Soc Trop Med Hyg. 1983;77:232-44.

11. Breman JG. Ears of the hippopotamus: manifestations, determinants, and estimates of the malaria burden. In: Breman JG, Egan A, Keusch GT, editors. The intolerable burden of malaria: a new look at the numbers. Am J Trop Med Hyg. 2001;64 Suppl 1:1-11.

12. Danwang C, Bigma JJ, TukuNzalie RN, Robert A. Epidemiology of clinical congenital and neonatal malaria in endemic settings: a systematic review and meta-analysis. Malar J. 2020:19:312.
13. Bilal JA, Malik EE, Al-Nafeesah A, Adam I. Global prevalence of congenital malaria: a systematic review and meta-analysis. Eur J Obstet Gynecol Reprod Biol. 2020;252:534-42.

14. Osungbade $\mathrm{KO}$, Oladunjoye $\mathrm{OO}$. Prevention of congenital transmission of malaria in sub-Saharan African countries: challenges and implications for health system strengthening. J Trop Med. 2012;2012:648456.

15. Menendez C, Mayor A. Congenital malaria: the least known consequence of malaria in pregnancy. Semin Fetal Neonatal Med. 2007;12:207-13.

16. Mohan K, Mr BJ, Singh RD, Maithani MM, Chaurais RN. The clinico-hematological features and management outcome in neonatal malaria: a nine years analysis from North India. Curr Pediatr Rev. 2016;12:286-91.

17 WHO. Severe falciparum malaria. Trans R Soc Trop Med Hyg. 2000:94:S1-90.

18. Idro R, Marsh K, John CC, Newton CRJ. Cerebral malaria: mechanisms of brain injury and strategies for improved neuro-cognitive outcome. Pediatr Res. 2010:68:267-74.

19. Volpe JJ. Neonatal seizures: current concepts and revisedclassification. Pediatrics. 1989:84:422-8.

20. Fenichel GM, Olson BJ, Fitzpatrick JE. Heart rate changes in convulsive and nonconvulsive neonatal apnea. Ann Neurol. 1980;7:577-82.

21. Menendez C, Bardaji A, Sigauque B, Sanz S, Aponte JJ, Mabunda S, et al. Malaria prevention with IPTp during pregnancy reduces neonatal mortality. PLoS ONE. 2010;5:e9438.

22. WHO. Malaria Policy Advisory Committee Meeting Report. Geneva: World Health Organization; 2019. http://iris.wpro.who.int/handle/10665.1/ 10945.

23. Federal Ministry of Health, National Malaria Control Programme. Strategic Plan 2009-2013: a road map for malaria control in Nigeria. Abuja: Federal Ministry of Health; 2008.

24 National Population Commission Nigeria. Nigeria demographic and health survey 2018: key indicators. Abuja: National Population Commission Nigeria; 2019.

25. Ekanem AD, Anah MU, Udo JJ. The prevalence of congenital malaria among neonates with suspected sepsis in Calabar, Nigeria. Trop Doct. 2008:38:73-6.

26. Falade C, Mokuolu O, Okafor H, Orogade A, Falade A, Adedoyin O, et al. Epidemiology of congenital malaria in Nigeria: a multi-centre study. Trop Med Int Health. 2007;12:1279-87.

27. Olowu JA, Sowunmi A, Abohweyere AEJ. Congenital malaria in Nigeria: a revisit. Afr J Med Med Sci. 2000;29:211-3.

28. Valecha N, Bhatia S, Mehta S, Nehta S, Dash AP. Congenital malaria with atypical presentation: a case report from low transmission area in India. Malar J. 2007;6:43

29. Vedang S, Mohite M. Congenital cerebral malaria with malarial hepatitis. Pediatr Infect Dis. 2010;2:112-4.

30. Saghir S, Moukit M, Kouach J, Assoufi N, Abilkassem R, Adagr A. What about the treatment of asymptomatic forms of congenital malaria: case report and review of the literature. Pan Afr Med J. 2020;35:116.

31. Obiajunwa PO, Owa JA, Adeodu OO. Prevalence of congenital malaria in Ile-Ife, Nigeria. J Trop Pediatr. 2005;51:219-22.

32. Baspinar O, Bayraktaroglu Z, Karsligli T, Bayram A, Coscun Y. A rare case of anemia and thrombocytopenia in a newborn: congenital malaria. Turk J Pediatr. 2006:48:63-5.

33. Fischer PR. Malaria and newborns. J Trop Pediatr. 2003;49:132-5.

34. Newton CRJC, Hien TT, White N. Cerebral malaria. J Neurol Neurosurg Psychiatry. 2000;69:433-41.

35. Punta VD, Gulletta M, Matteelli A, Spinoni V, Regazzolli A, Castelli F. Congenital Plasmodium vivax malaria mimicking neonatal sepsis: a case report. Malar J. 2010;9:63.

36. WHO. Report of WHO technical consultation. Parasitological confirmation of malaria diagnosis. Geneva: World Health Organization; 2009. http:// whqlibdoc.who.int/publications/2010/9789241599412_eng.pdf.

37. Balaka B, Agbere AD, Bonkoungou P, Kessie K, Assimadi K, Agbo K. Congenital malarial disease due to Plasmodium falciparum in high-infectionrisk newborn. Arch Pediatr. 2000;7:243-8.

38. Sumbelle IU, Ning TR, Bopda OS, Nkuo-Akenji T. Variation in malariometric and red cell indices in children in the Mount Cameroon area following enhanced malaria control measures: evidence from a repeated crosssectional study. Malar J. 2014;13:334

39. Koram KA, Owusu-Agyei S, Utz G, Binka FN, Baird JK, Hoffman SL, et al. Severe anaemia in young children after high and low malaria 
transmission seasons in the Kassena-Nankana district of Northern Ghana. Am J Trop Med Hyg. 2000;62:670-4.

40. WHO. Guidelines for the treatment of malaria. Geneva: World Health

Organization; 2010. https://whqlibdoc.who.int/publications/2010/97892 41547925_eng.pdf.

41. Ehrenreich $H$, Hasselblatt M, Dembowski C, Cepek L, Lewczuk P, Stiefel M, et al. Erythropoietin therapy for acute stroke is both safe and beneficial. Mol Med. 2002;8:495-505.

\section{Publisher's Note}

Springer Nature remains neutral with regard to jurisdictional claims in published maps and institutional affiliations.

Ready to submit your research? Choose BMC and benefit from:

- fast, convenient online submission

- thorough peer review by experienced researchers in your field

- rapid publication on acceptance

- support for research data, including large and complex data types

- gold Open Access which fosters wider collaboration and increased citations

- maximum visibility for your research: over $100 \mathrm{M}$ website views per year

At $\mathrm{BMC}$, research is always in progress.

Learn more biomedcentral.com/submissions 